\title{
Factors Affecting Discharge to Home of Medical Patients Treated in an Intensive Care Unit
}

\author{
Takayuki Shimogai ${ }^{1,2,3}$, Kazuhiro P. Izawa ${ }^{1,3, * \mathbb{C}}$, Minoru Kawada ${ }^{4}$ and Akira Kuriyama ${ }^{5}$ \\ 1 Department of Public Health, Graduate School of Health Sciences, Kobe University, Kobe 654-0142, Japan; \\ tak813hir@gmail.com \\ 2 Department of Rehabilitation, Kobe City Medical Center General Hospital, Kobe 650-0047, Japan \\ 3 Cardiovascular Stroke Renal Project (CRP), Kobe 654-0142, Japan \\ 4 Department of Rehabilitation, Kurashiki Central Hospital, Kurashiki 710-8602, Japan; \\ mkawada0805@gmail.com \\ 5 Emergency and Critical Care Center, Kurashiki Central Hospital, Kurashiki 710-8602, Japan; \\ ak13568@kchnet.or.jp \\ * Correspondence: izawapk@harbor.kobe-u.ac.jp; Tel.: +81-78-796-4566
}

Received: 23 September 2019; Accepted: 5 November 2019; Published: 6 November 2019

\begin{abstract}
The purpose of this study was to examine the factors affecting the discharge to home of medical patients treated in an intensive care unit, including elements of in-hospital rehabilitation and prehospital movement ability. The participants of this retrospective cohort study were medical patients treated in an intensive care unit (ICU) and who began rehabilitation in ICU. We assessed the participants in the ICU and analyzed data on patient background, hospitalization, and rehabilitation status. There were 155 ICU patients available for analysis. A multivariable logistic regression model identified the four variables of age (OR 1.06, 95\% CI 1.02-1.09), APACHE II score (OR 1.12, 95\% CI 1.04-1.24), independence in home life before admission (OR 7.10, 95\% CI 1.65-30.44), and standing within 5 days of admission (OR 6.58, 95\% CI 2.60-16.61) as factors significantly related to discharge from hospital to home. Independence of home life before admission and early start of standing were identified as factors strongly related to discharge to home. The degree of independence in living before hospital admission and progress toward early mobilization are helpful when considering an ICU patient's discharge destination.
\end{abstract}

Keywords: intensive care unit; medical patients; discharge; rehabilitation; early mobilization; physical therapy

\section{Introduction}

In the critical care area, intensive care management has improved over the last decade. As a result, the survival rate of critically ill patients has improved [1,2], and the outcome after discharge following treatment in an intensive care unit (ICU) can vary. For example, some ICU patients recover within a short time and are discharged to home (defined as being discharged from the hospital directly to home without transfer to another facility such as an intermediate care facility or nursing home), others cannot fully recover their function after discharge, some require long-term hospitalization and further care after hospital discharge, and some patients enter nursing homes [3,4].

Also, the rate of direct-to-home discharges from the ICU also tend to increase [5] because the beds in the ICU and on wards are becoming unavailable and the support of local communities and the quality of medical care have improved [6].

In fact, it is reported that about $25 \%$ to $45 \%$ of patients treated in the ICU were not discharged home [3,7]. In addition, $31.6 \%$ of such patients are rehospitalized within 30 days, and the rate of unplanned readmission is reported to be $23.2 \%$ [8]. 
If ICU patients can be discharged to the next appropriate destination, their duration of hospitalization can be shortened, which will reduce iatrogenic morbidity and lead to cost reductions and effective use of medical resources [5]. With the diversification of sites to which patients can be discharged and to determine the correct discharge destination, it is important to decide which ICU patients can be transferred to a care facility and or safely return home. For this purpose, it is necessary to evaluate the risk factors related to home discharge during hospitalization.

In this current situation, some reports have examined the risk factors of discharge outcome. Harrison et al. suggested dementia and elderly women with high dependence as predictors of discharge to a long-term care facility after acute admission [9]. As well, mechanically-ventilated patients and those with severe cognitive dysfunction or poor physical function and/or mobility difficulties are also at risk for discharge to a nursing home [7].

Rehabilitation strategies for severely-ill emergency patients are said to promote the restoration of previous activity with respect to muscle strength and ability [10]. One of the effects of early rehabilitation in the ICU also relates to early improvement of the activities of daily living (ADL) [11,12]. In addition, early mobilization is reported to improve the rate of discharge to home of patients who were treated with mechanical ventilation in the ICU [13].

Therefore, factors related to the state of rehabilitation in ICU patients should be taken into consideration when planning discharge. Nevertheless, in relation to these previously mentioned factors $[6,7,9,13]$, no studies of factors related to discharge have considered the effects of early rehabilitation in the ICU during hospitalization.

Thus, we hypothesized that early rehabilitation might be associated with discharge to home of ICU patients. Based on this hypothesis, the purpose of this study was to examine the factors affecting discharge to home of medical patients in the ICU.

\section{Materials and Methods}

\subsection{Study Design and Patients}

This was a retrospective cohort study conducted from April 2013 to June 2015 in the Emergency and Critical Care Center of Kurashiki Central Hospital, Kurashiki, Japan.

Consecutive participants were recruited between April 2013 and June 2015. Participants included medical patients who were treated in and also started rehabilitation in the ICU. Patients were excluded from the study for the following reasons: transfer to a general ward with no rehabilitation occurring in the ICU, death during hospitalization, refusal of rehabilitation.

\subsection{Study Procedures}

We collected data on patient background, hospitalization, and rehabilitation status.

Patient background included disease (classified by the International Statistical Classification of Diseases and Related Health Problems 10th Revision (ICD-10)), age, sex, body mass index, SOFA (Sequential Organ Failure Assessment) score [14], APACHE II (Acute Physiology and Chronic Health Evaluation II) score [15], criteria for evaluating the degree of independence (degree of "bed riddenness") of the disabled elderly patients in performing ADL before admission, and the rate of living alone.

Variables during hospitalization included serum albumin ( $\mathrm{Alb}$ ) value at the times of admission and discharge, peak value of C-reactive protein during hospitalization (peak CRP), peak white blood cell count while hospitalized (peak WBC), use of cardiotonic drugs, Medical Research Council (MRC) score at the beginning and end of rehabilitation at discharge, diagnosis of delirium, treatment with mechanical ventilation, and length of hospital stay in days.

Status of rehabilitation included the number of days from admission to the start of rehabilitation, the first time the patient sat at the edge of the bed, start of standing within 5 days of admission, and the Functional Independence Measure score (FIM; exercise items and cognitive items) [16] at the start and end of rehabilitation. 


\subsection{Criteria for Evaluation of ADL Before Admission}

“Criteria for evaluating the degree of independence (degree of 'bed riddenness') of disabled elderly persons in performing activities of daily living (in Japanese)" are criteria proposed by the Ministry of Health, Labor and Welfare of Japan, and although not internationally standardized [17,18], they are widely used in Japan [19]. In this standard, subjects classified as rank J have some degree of disability, but they are almost completely independent in daily activities and can go out without assistance. Subjects classified as Rank A are almost independent in everyday life activities but cannot go out without assistance. Subjects classified as Rank B require a certain level of assistance to carry out indoor activities and are mainly confined to bed day and night, but they can sit on the bed. Subjects classified as Rank $C$ are bed-ridden and require assistance for toileting, eating, and changing of clothes [18].

In the present study, we used these as the criteria of ADL before admission. In addition, we defined the patients of ranks $\mathrm{J}$ and $\mathrm{A}$ as having independence in home life and the patients of ranks $\mathrm{B}$ and $\mathrm{C}$ as being bedridden and divided the patients according to these two pre-hospital ADL abilities.

\subsection{Assessment of Muscle Strength}

After the patient awoke on the morning following the first day of admission or regained consciousness if unconscious, muscle strength was measured in all four limbs using the MRC scale, which uses values ranging from 0 (tetraplegia) to 60 (normal muscle strength) [20]. This scale is a graded summation of the strength of 6 muscle groups tested bilaterally. These muscle groups are the arm abductors, forearm flexors, wrist extensors, leg flexors, knee extensors, and dorsal foot flexors. The MRC scale score is calculated by recording the muscle strength scores according to 5 grades of power for the 6 muscle groups, each on the left and right, and summing the scores [20].

\subsection{Assessment of Disability}

The ability to sit on the edge of the bed is referred to as sitting ability of Hoffer's classification [21], which represents that the patient sits on the edge of the bed with his/her feet on the floor and releases his/her hands from the bed. The patient is then evaluated according to three classifications: maintains a stable sitting position (independent sitter), holds a sitting position with support of the hands (hands-dependent sitter), or impossible to sit (propped sitter). In this study, when sitting on the edge of the bed was performed for the first time, maintenance of a sitting position was defined if the patient was either an independent sitter or hands-dependent sitter.

We considered "standing up" as the point at which a patient's activity greatly increases for rehabilitation, and thus we included standing within 5 days of admission in the measurement items. In Europe and the United States, early mobilization is considered to be physical activity that takes place within 2 to 5 days of admission [22,23]. Therefore, we defined patients who could stand within 5 days of admission as getting up early.

\subsection{Ethical Considerations}

This study is in accordance with the Declaration of Helsinki. The Kurashiki Central Hospital Institutional Review Committee on Human Research approved this study (approval no. 1898). This study omitted patient consent because of a retrospective study.

\subsection{Statistical Analysis}

We classified the patients who were discharged from our hospital to home into the home discharge group and those who were transferred from our hospital to another care facility into the transfer group. Univariate analysis was used to compare each item of the patient's background, variables during hospitalization, and rehabilitation status between the home discharge group and the transfer group. 
Comparisons were performed using a Mann-Whitney $U$ test for continuous variables, and chi-square test for binary variables. A two-tailed $p$-value $<0.05$ was considered to indicate statistical significance.

Multivariable logistic regression models were used to examine the effect of the variables on home discharge of the ICU patients. Selection of variables was based on previous literature $[5,6]$. Patients discharged directly to home from the ICU have been found to be young, healthy, and to have fewer comorbidities than those not discharged directly to home $[5,6]$. For this reason, we added age and the APACHE II score as variables in this multivariate analysis. The final multivariable model was developed by including the variables whose statistical significance was $p \leq 0.05$, and the variables considered to be multi-collinear were excluded. We simultaneously entered variables that we considered the risk factors of discharge to home of the patients in the multivariate logistic regression. Statistical analysis was performed by IBM SPSS $24.0 \mathrm{~J}$ statistical software (IBM SPSS Japan, Inc., Tokyo, Japan).

\section{Results}

From April 2013 to July 2015, 1166 consecutive patients were admitted to our emergency medical center in Kurashiki Central Hospital. Among these, the ICU physicians requested rehabilitation for 518 patients. Among them, 197 patients were included the rehabilitation cases started in ICU. 42 patients (with cerebrovascular disease who were transferred to the stroke unit, death, denied rehabilitation and missing data for the evaluation items) were excluded. As a result, 155 patients were included in the final analysis (Figure 1). About two-thirds $(n=95,61.3 \%)$ of these patients were discharged home directly from our hospital.

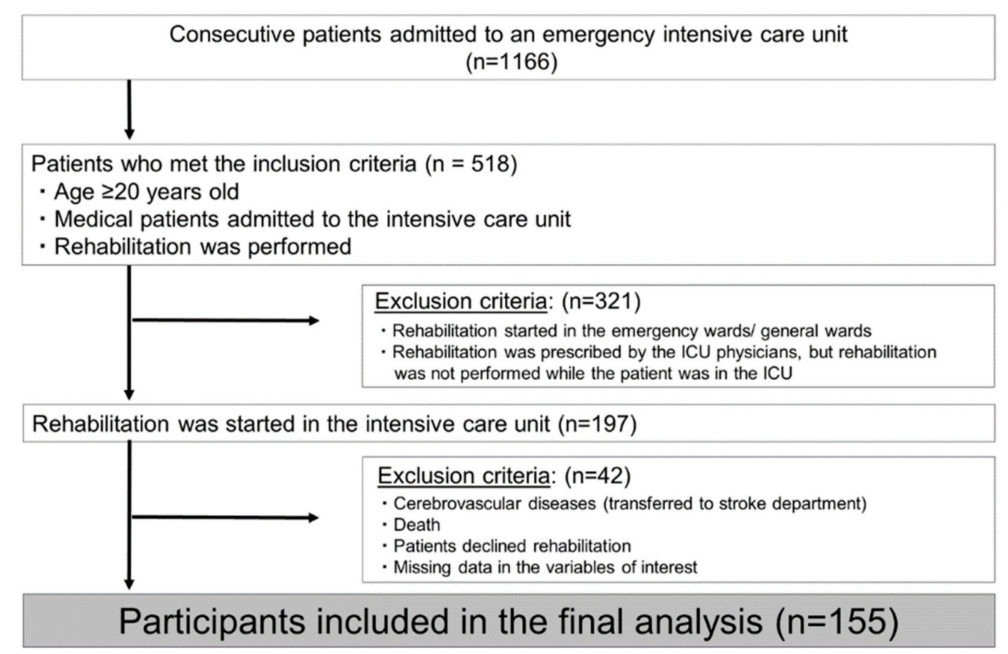

Figure 1. Flow of patient selection.

Patient characteristics of the study cohort are shown in Table 1. As a result of classification based on the ICD-10, the distribution of patients mostly comprised those with sepsis and respiratory diseases, followed by digestive system diseases. 
Table 1. Patient characteristics (classified according to the ICD-10*).

\begin{tabular}{|c|c|c|}
\hline Major Classification & $\mathbf{n}$ & Minor Classification \\
\hline I. Certain infectious and parasitic diseases & 46 & Sepsis 46 \\
\hline$X$. Diseases of the respiratory system & 37 & $\begin{array}{l}\text { Chronic obstructive pulmonary disease (COPD) - acute } \\
\text { exacerbation } 4 \text {, interstitial pulmonary diseases } 5 \text {, asthma } 3 \text {, } \\
\text { hemorrhage from other sites in respiratory passages } 1 \text {, bacterial } \\
\text { pneumonia } 14 \text {, pneumonitis due to food and vomiting } 1 \text {, } \\
\text { drug-induced interstitial lung disorders, unspecified } 2 \text {, } \\
\text { drowning and nonfatal submersion } 2 \text {, bronchus or lung, } \\
\text { unspecified } 1 \text {, acute respiratory failure } 3 \text {, other and unspecified } \\
\text { abnormalities of breathing }\left(\mathrm{CO}_{2} \text { narcosis }\right) 1\end{array}$ \\
\hline XI. Diseases of the digestive system & 21 & $\begin{array}{l}\text { Gastrointestinal hemorrhage } 12 \text {, acute pancreatitis } 5 \text {, esophageal } \\
\text { varices } 2 \text {, gastric ulcer } 1 \text {, peritonitis } 1\end{array}$ \\
\hline $\begin{array}{l}\text { XIX. Injury, poisoning and certain other } \\
\text { consequences of external causes }\end{array}$ & 18 & $\begin{array}{l}\text { Other and unspecified drugs/medicaments and biological } \\
\text { substance (acute drug addiction) 13, hypothermia 2, injury of } \\
\text { muscles and tendons of unspecified body region 1, injury of } \\
\text { intercostal blood vessels 1, toxic effect of carbon monoxide } 1\end{array}$ \\
\hline VI. Diseases of the nervous system & 7 & $\begin{array}{l}\text { Encephalitis, myelitis and encephalomyelitis 3, epilepsy 2, } \\
\text { disorder of autonomic nervous system 1, myasthenia gravis } 1\end{array}$ \\
\hline $\begin{array}{l}\text { XVIII. Symptoms, signs and abnormal clinical and } \\
\text { laboratory findings, not elsewhere classified }\end{array}$ & 3 & $\begin{array}{l}\text { Coma, unspecified 1, unspecified adverse effect of drug or } \\
\text { medicament (serotonin syndrome) } 1 \text {, Hemoptysis } 1\end{array}$ \\
\hline XIV. Diseases of the genitourinary system & 5 & Acute renal failure 5 \\
\hline IX. Diseases of the circulatory system & 1 & Cardiac arrest 1 \\
\hline XII. Diseases of the skin and subcutaneous tissue & 1 & Bullous erythema multiforme (Stevens-Johnson syndrome) 1 \\
\hline
\end{tabular}

* International Statistical Classification of Diseases and Related Health Problems 10th Revision.

Among patient background variables, there were significant differences between the two groups in terms of age, SOFA, APACHE II score, and ADL before hospitalization. Among the hospitalization variables, significant differences between the two groups were confirmed for Alb at hospitalization and MRC score at the start of rehabilitation (Table 2).

Table 2. Summary comparing home discharge and transfer.

\begin{tabular}{|c|c|c|c|}
\hline & Home Discharge & Transfer & \multirow{2}{*}{ P-Value } \\
\hline & $\mathrm{n}=95$ & $\mathrm{n}=60$ & \\
\hline Age & $66.0(51.0,74.0)^{*}$ & $75.5(65.8,82.3) *$ & $<0.001$ \\
\hline Sex (male/female) & $61 / 34$ & $37 / 23$ & 0.75 \\
\hline SOFA score & $6.0(3.5,9.0) *$ & $7.0(4.8,9.3) *$ & 0.049 \\
\hline APACHE II score & $16.0(11.5,20.0) *$ & $21.5(15.0,25.0) *$ & $<0.001$ \\
\hline Independence at home before admission (\%) & $95.8 \%(91 / 95)$ & $76.7 \%(46 / 60)$ & $<0.001$ \\
\hline Peak CRP $(\mathrm{mg} / \mathrm{L})$ & $10.32(4.16,17.14)$ * & $14.88(5.69,19.74)$ * & 0.26 \\
\hline Peak WBC $\left(\times 10^{3} / \mu \mathrm{L}\right)$ & $14.20(10.05,18.90)$ * & $15.25(10.00,21.47) *$ & 0.39 \\
\hline Admission albumen (g/dL) & $3.00(2.60,3.80) *$ & $2.70(2.20,3.40) *$ & 0.009 \\
\hline Use of cardiotonic drugs (\%) & $23.2 \%(22 / 95)$ & $35.0 \%(21 / 60)$ & 0.109 \\
\hline Mechanical ventilation $(\%)$ & $74.7 \%(71 / 95)$ & $73.3 \%(44 / 60)$ & 0.85 \\
\hline Delirium $(\%)$ & $9.5(9 / 95)$ & $16.7(10 / 60)$ & 0.184 \\
\hline Rehabilitation start date (day) & $1.0(1.0,2.0) *$ & $1.0(1.0,2.0)^{*}$ & 0.59 \\
\hline Initial MRC score & $52(48,55) *$ & $46(37,49.5) *$ & $<0.001$ \\
\hline Hands-dependent sitter (\%) & $89.5(85 / 95)$ & $51.7(31 / 60)$ & $<0.001$ \\
\hline Standing within 5 days of admission (\%) & $84.2(80 / 95)$ & $51.7(31 / 60)$ & $<0.001$ \\
\hline Motor FIM (start) & $13.0(13.0,16.5)$ * & $13.0(13.0,13.0)$ * & 0.012 \\
\hline Cognitive FIM (start) & $23.0(10.5,29.0) *$ & $5.5(5.0,14.3) *$ & $<0.001$ \\
\hline Hospital stay (days) & $18.0(12.0,29.0)$ * & $29.5(19.0,49.8)$ * & $<0.001$ \\
\hline
\end{tabular}

Legends: SOFA, Sepsis-related Organ Failure Assessment; APACHE II, Acute Physiology and Chronic Health Evaluation II; CRP, C-reactive protein; WBC, white blood cell; MRC, Medical Research Council; FIM, Functional Independence Measure. *Median (interquartile range (IQR)): Continuous data are presented as median and IQR. Categorical data (including sex and discharge diagnoses) are presented as total number and percentage in this study. 
Among the variables on rehabilitation between the two groups, significant differences were present for the start date of standing within 5 days of admission, length of hospital stay, and FIM (motor/cognitive) at the start of rehabilitation.

The results of the multivariable analysis are reported in Table 3. The multivariable logistic regression model showed the following four variables to be significantly associated with an increased rate of home discharge: age (OR 1.06, 95\% CI 1.02-1.09), APACHE II score (OR 1.12, 95\% CI 1.04-1.24), independence in home life before admission (OR 7.10, 95\% CI 1.65-30.44), and standing within 5 days of admission (OR 6.58, 95\% CI 2.60-16.61). The model showed good calibration (Hosmer-Lemeshow Goodness-of-Fit test: $\mathrm{p}=0.63$, percentage of correct classifications: $79.4 \%$ ).

Table 3. Multivariate analysis of factors relating to home discharge or transfer*.

\begin{tabular}{cccc}
\hline Variable & P-Value & OR & 95\% CI \\
\hline Age & 0.001 & 1.06 & $1.02-1.09$ \\
APACHE II score & 0.002 & 1.12 & $1.04-1.20$ \\
Independence at home before admission & 0.008 & 7.10 & $1.65-30.44$ \\
Standing within 5 days of admission & $<0.001$ & 6.58 & $2.60-16.61$ \\
\hline
\end{tabular}

OR, odds ratio; CI, confidence interval; APACHE, Acute Physiology and Chronic Health Evaluation. ${ }^{*}$ Hosmer-Lemeshow test, $\mathrm{p}=0.958$. Percentage of correct classifications: $79.4 \%$.

\section{Discussion}

The present study suggested that age, independence in home life before admission, APACHE II score, standing within 5 days of admission, and admission Alb value were the independent factors related to discharge to home of medical patients admitted to an ICU. In particular, independence in home life before admission and standing within 5 days of admission were the strongest factors affecting discharge to home.

\subsection{Independence at Home Before Admission}

In ICU patients or general medical patients, the important variable that predicts hospital outcome is reported to be the baseline level of activity at admission [24,25]. Furthermore, another previous study suggests that pre-ICU frailty is associated with increased post-ICU disability and the rate of new nursing home admissions [26]. From these facts, independence at home before admission is important as a predictive factor related to home discharge, and this was suggested from our research results.

\subsection{Starting Date of Standing}

Rehabilitation for ICU patients with critical illness is important to aid in their return to prehospital activity [10]. In particular, a recent meta-analysis concluded that early rehabilitation can increase the possibility of walking without assistance at hospital discharge [12]. Early rehabilitation in the ICU has been shown to improve the subsequent ADL of hospitalized patients [11,27]. It has also been reported that physical function leading to reacquisition of ADL can be improved by getting the patient out of bed early and engaging them in active exercise from an early stage [28,29]. It is important for patients to stand as soon as possible from the results of this study. Therefore, for ICU patients, we recommend conducting a program of early rehabilitation, including standing at the bedside, to help return ADL capabilities at discharge.

\subsection{Factors Affecting Discharge to Home}

Lower age and higher test scores (The Physical Function in Intensive Care Test (PFIT-s), Functional Status Score for the ICU (FSS-ICU), and ICU Mobility Scale (IMS)) at ICU discharge are significant factors in determining discharge to home [30]. Also, older ICU survivors with a low burden of comorbidities and little to no disability at hospital discharge have generally good outcomes [31,32]. 
The risk for discharge to a care facility was greatest for hospitalized patients characterized as having poor strength and/or mobility [7].

From these findings, early rehabilitation is important for achieving a good outcome as it is largely related to ADL independence before admission and mobility after hospitalization, and to age, disease, and complications. Thus, all of these factors need to be evaluated when determining the appropriateness of discharge to home of patients treated in the ICU. As indicated by this study, the patient's degree of independence in living before admission to the hospital and the progress made toward early mobilization also help when considering the discharge destination.

\subsection{Implications}

To our knowledge, this is the first study to show that the progress of in-hospital rehabilitation is a relevant factor related to discharge to home of medical patients admitted to an ICU. ICU rehabilitation offers many benefits, including reduced length of ICU and hospital stays, increased number of ventilator-free days, and improved peripheral and respiratory muscle strength, physical function, and health-related quality of life (HRQOL) [11,12]. In addition to these existing reports, the results of this study may encourage rethinking of the implications of early rehabilitation and the consideration of interventions to reduce the need for discharge to places other than home. As the present study shows, it is clear that discharge to home is related to various factors, and further study should be undertaken in a prospectively to determine whether discharge outcomes improve when adjusting variables based on the results.

\subsection{Limitations}

There are some limitations in our present study. First, this study is for patients with medical diseases in ICU. We summarized the patient characteristics of the disease using ICD-10, and as a result, classified into many disease types. Although there were various types of diseases, we were unable to investigate the course of each individual disease because this study targets all medical diseases. Second, this study was a retrospective study, and we failed to investigate some potentially important factors might not have been investigated due to the lack of such data. For example, some test scores (PFIT-s, FSS-ICU, and IMS) and comorbidities are reportedly factors that determine home discharge when leaving the ICU [30-32]. However, this study could not investigate them during the hospitalization. Further, the participants in this study were relatively old. The presence of family members and caregivers, the home environment, and home care services may be important when clinicians consider discharging patients to home; however, we failed to investigate the impact of these factors due to the lack of such data. Prospective studies that examine whether these factors have an influence on the discharge destination of ICU patients. Third, this is a single-center study that was conducted in a representative city of Japan. Although it seems to reflect the general population in Japan, regional characteristics must be considered when planning patient discharge.

\section{Conclusions}

This We identified factors affecting discharge to home of medical patients treated in an ICU. In addition to generally reported factors such as age and illness severity, independence in the patients before admission home life and their ability to stand early after admission were identified. Therefore, the degree of independence in home life before admission to hospital and the progress of early mobilization should aid in considering the appropriate discharge destination of ICU patients.

Author Contributions: T.S. prepared the manuscript and researched the literature. T.S. and M.K. conceived and designed the study. T.S. and M.K. collected the data. T.S. and K.P.I. analyzed the data. T.S., K.P.I, M.K., and A.K. drafted or critically revised the manuscript for important intellectual content.

Funding: This research received no external funding. 
Acknowledgments: We thank the staff members of Kurashiki Central Hospital and Kobe University who collaborated in this study. This study was also benefitted by the support and encouragement of Tamami Kitano, Chieko Kaneda, and Reiko Ohara of the Faculty of Health Sciences, Kobe University, and Yuji Kanejima, Hiroto Ogi, Ikko Kubo, Asami Ogura, Kodai Ishihara, Masashi Kanai, Masato Ogawa, Masahiro Kitamura, and Shinichi Shimada, all of the Graduate School of Health Sciences, Kobe University. We also thank Minato Nakazawa, Department of Public Health, Graduate School of Health Sciences, Kobe University, for statistical support of the present study.

Conflicts of Interest: The authors declare no conflict of interest.

\section{References}

1. Kaukonen, K.M.; Bailey, M.; Suzuki, S.; Pilcher, D.; Bellomo, R. Mortality related to severe sepsis and septic shock among critically ill patients in Australia and New Zealand, 2000-2012. JAMA 2014, 311, 1308-1316. [CrossRef] [PubMed]

2. Iwashyna, T.J.; Cooke, C.R.; Wunsch, H.; Kahn, J.M. Population burden of long-term survivorship after severe sepsis in older Americans. J. Am. Geriatr. Soc. 2012, 60, 1070-1077. [CrossRef] [PubMed]

3. Reineck, L.A.; Pike, F.; Le, T.Q.; Cicero, B.D.; Iwashyna, T.J.; Kahn, J.M. Hospital factors associated with discharge bias in ICU performance measurement. Crit. Care Med. 2014, 42, 1055-1064. [CrossRef] [PubMed]

4. Creditor, M.C. Hazards of hospitalization of the elderly. Ann. Intern. Med. 1993, 118, 219-223. [CrossRef]

5. Basmaji, J.; Lau, V.; Lam, J.; Priestap, F.; Ball, I.M. Lessons learned and new directions regarding Discharge Direct from Adult Intensive Care Units Sent Home (DISH): A narrative review. J. Intensive Care Soc. 2019, 20, 165-170. [CrossRef] [PubMed]

6. Lau, V.I.; Priestap, F.A.; Lam, J.N.H.; Ball, I.M. Factors Associated with the Increasing Rates of Discharges Directly Home from Intensive Care Units-A Direct from ICU Sent Home Study. J. Intensive Care Med. 2018, 33, 121-127. [CrossRef] [PubMed]

7. Gehlbach, B.K.; Salamanca, V.R.; Levitt, J.E.; Sachs, G.A.; Sweeney, M.K.; Pohlman, A.S.; Charbeneau, J.; Krishnan, J.A.; Hall, J.B. Patient-related factors associated with hospital discharge to a care facility after critical illness. Am. J. Crit. Care 2011, 20, 378-386. [CrossRef]

8. Chawla, S.; D’Agostino, R.L.; Pastores, S.M.; Thirumala, R.; Kostelecky, N.; Chou, J.F.; Thaler, H.T.; Halpern, N.A. Homeward bound: An analysis of patients discharged home from an oncologic intensive care unit. J. Crit. Care 2012, 27, 681-687. [CrossRef]

9. Harrison, J.K.; Walesby, K.E.; Hamilton, L.; Armstrong, C.; Starr, J.M.; Reynish, E.L.; MacLullich, A.M.J.; Quinn, T.J.; Shenkin, S.D. Predicting discharge to institutional long-term care following acute hospitalisation: A systematic review and meta-analysis. Age Ageing 2017, 46, 547-558. [CrossRef]

10. Centre for Clinical Practice at NICE. National Institute for Health and Clinical Excellence: Guidance. In Rehabilitation after Critical Illness; National Institute for Health and Clinical Excellence (UK): London, UK, 2009.

11. Morris, P.E.; Goad, A.; Thompson, C.; Taylor, K.; Harry, B.; Passmore, L.; Ross, A.; Anderson, L.; Baker, S.; Sanchez, M.; et al. Early intensive care unit mobility therapy in the treatment of acute respiratory failure. Crit. Care Med. 2008, 36, 2238-2243. [CrossRef]

12. Kayambu, G.; Boots, R.; Paratz, J. Physical therapy for the critically ill in the ICU: A systematic review and meta-analysis. Crit. Care Med. 2013, 41, 1543-1554. [CrossRef] [PubMed]

13. Ota, H.; Kawai, H.; Sato, M.; Ito, K.; Fujishima, S.; Suzuki, H. Effect of early mobilization on discharge disposition of mechanically ventilated patients. J. Phys. Ther. Sci. 2015, 27, 859-864. [CrossRef] [PubMed]

14. Vincent, J.L.; Moreno, R.; Takala, J.; Willatts, S.; De Mendonca, A.; Bruining, H.; Reinhart, C.K.; Suter, P.M.; Thijs, L.G. The SOFA (Sepsis-related Organ Failure Assessment) score to describe organ dysfunction/failure. On behalf of the Working Group on Sepsis-Related Problems of the European Society of Intensive Care Medicine. Intensive Care Med. 1996, 22, 707-710. [CrossRef] [PubMed]

15. Knaus, W.A.; Draper, E.A.; Wagner, D.P.; Zimmerman, J.E. APACHE II: A severity of disease classification system. Crit. Care Med. 1985, 13, 818-829. [CrossRef] [PubMed]

16. Hamilton, B.B.; Laughlin, J.A.; Fiedler, R.C.; Granger, C.V. Interrater reliability of the 7-level functional independence measure (FIM). Scand. J. Rehabil. Med. 1994, 26, 115-119. 
17. An Official Decument of Ministry Secretariat of Health and Welfare for the Elderly Bureau. Criteria for Evaluating the Degree of Independence (Degree of "Bedriddenness") of Disabled Elderly Persons in Performing Activities of Daily Living; Rohken publication, 1991. (In Japanese)

18. Uza, M.; Tome, K.; Imai, M.; Danboku, K.; Suzuki, M. A study of case finding of the latent bedridden elderly using criteria of activity of daily living. Jpn. J. Health Hum. Ecol. 1997, 63, 79-89. [CrossRef]

19. Tsuga, K.; Yoshikawa, M.; Oue, H.; Okazaki, Y.; Tsuchioka, H.; Maruyama, M.; Yoshida, M.; Akagawa, Y.J.G. Maximal voluntary tongue pressure is decreased in Japanese frail elderly persons. Gerodontology 2012, 29, e1078-e1085. [CrossRef]

20. Kleyweg, R.P.; van der Meche, F.G.; Schmitz, P.I. Interobserver agreement in the assessment of muscle strength and functional abilities in Guillain-Barre syndrome. Muscle Nerve 1991, 14, 1103-1109. [CrossRef]

21. Hoffer, M.M. Basic considerations and classifications of cerebral palsy. Am. Acad. Orthop. Surg. Instr. Course Lect. 1976, 25, 37.

22. Hodgson, C.L.; Berney, S.; Harrold, M.; Saxena, M.; Bellomo, R. Clinical review: Early patient mobilization in the ICU. Crit. Care 2013, 17, 207. [CrossRef]

23. Cameron, S.; Ball, I.; Cepinskas, G.; Choong, K.; Doherty, T.J.; Ellis, C.G.; Martin, C.M.; Mele, T.S.; Sharpe, M.; Shoemaker, J.K.; et al. Early mobilization in the critical care unit: A review of adult and pediatric literature. J. Crit. Care 2015, 30, 664-672. [CrossRef] [PubMed]

24. Covinsky, K.E.; Justice, A.C.; Rosenthal, G.E.; Palmer, R.M.; Landefeld, C.S. Measuring prognosis and case mix in hospitalized elders: The importance of functional status. J. Gen. Intern. Med. 1997, 12, 203-208.

25. Nierman, D.M.; Schechter, C.B.; Cannon, L.M.; Meier, D.E. Outcome prediction model for very elderly critically ill patients. Crit. Care Med. 2001, 29, 1853-1859. [CrossRef] [PubMed]

26. Ferrante, L.E.; Pisani, M.A.; Murphy, T.E.; Gahbauer, E.A.; Leo-Summers, L.S.; Gill, T.M. The Association of Frailty with Post-ICU Disability, Nursing Home Admission, and Mortality: A Longitudinal Study. Chest 2018, 153, 1378-1386. [CrossRef] [PubMed]

27. Schweickert, W.D.; Kress, J.P. Implementing early mobilization interventions in mechanically ventilated patients in the ICU. Chest 2011, 140, 1612-1617. [CrossRef]

28. Adler, J.; Malone, D. Early mobilization in the intensive care unit: A systematic review. Cardiopulm. Phys. Ther. J. 2012, 23, 5-13. [CrossRef]

29. Sommers, J.; Engelbert, R.H.; Dettling-Ihnenfeldt, D.; Gosselink, R.; Spronk, P.E.; Nollet, F.; van der Schaaf, M. Physiotherapy in the intensive care unit: An evidence-based, expert driven, practical statement and rehabilitation recommendations. Clin. Rehabil. 2015, 29, 1051-1063. [CrossRef]

30. Parry, S.M.; Denehy, L.; Beach, L.J.; Berney, S.; Williamson, H.C.; Granger, C.L. Functional outcomes in ICU-What should we be using?-An observational study. Crit. Care 2015, 19, 127. [CrossRef]

31. Baldwin, M.R.; Narain, W.R.; Wunsch, H.; Schluger, N.W.; Cooke, J.T.; Maurer, M.S.; Rowe, J.W.; Lederer, D.J.; Bach, P.B. A Prognostic Model for 6-Month Mortality in Elderly Survivors of Critical Illness. Chest 2013, 143, 910-919. [CrossRef]

32. De Rooij, S.E.; Govers, A.C.; Korevaar, J.C.; Giesbers, A.W.; Levi, M.; de Jonge, E. Cognitive, functional, and quality-of-life outcomes of patients aged 80 and older who survived at least 1 year after planned or unplanned surgery or medical intensive care treatment. J. Am. Geriatr. Soc. 2008, 56, 816-822. [CrossRef]

(C) 2019 by the authors. Licensee MDPI, Basel, Switzerland. This article is an open access article distributed under the terms and conditions of the Creative Commons Attribution (CC BY) license (http://creativecommons.org/licenses/by/4.0/). 